\title{
Evaluation of glycopyrrolate in the treatment of chronic drooling
}

\author{
This article was published in the following Dove Press journal: \\ Degenerative Neurological and Neuromuscular Disease \\ 17 May 201I \\ Number of times this article has been viewed
}

\section{DS Reddihough ${ }^{1,2,3}$ \\ SM Reid 2,3 \\ C Plover'}

'Royal Children's Hospital, Melbourne, VIC, Australia; ${ }^{2}$ Murdoch Childrens Research Institute, Royal Children's Hospital, Melbourne, VIC, Australia; ${ }^{3}$ University of Melbourne, Melbourne, VIC, Australia
Correspondence: Dinah Reddihough Developmental Medicine Royal Children's Hospital, Flemington Road, Parkville, VIC 3052, Australia Tel +6I 393455898

Fax +6I 39345 587I

Email dinah.reddihough@rch.org.au
Abstract: Drooling is a major problem for children and adults with cerebral palsy and other neurological conditions. Medication is a major treatment option for these individuals. The focus of this review is to review glycopyrrolate, one of the frequently used medications for poor saliva control. Glycopyrrolate is a quaternary ammonium compound structurally related to atropine. The pharmacology, mode of action and pharmocokinetics are discussed, efficacy studies are reviewed, and safety and tolerability are described. Mention is made of the limited amount of information that is available on patient satisfaction and quality of life. Glycopyrrolate has an important place in the treatment of chronic drooling and possible uses for this medication are described. Further research would be helpful comparing glycopyrrolate with other anticholinergic medication and alternative treatments for drooling including botulinum toxins and surgical procedures.

Keywords: dribbling, poor saliva control, cerebral palsy, Parkinson Disease

\section{Management issues for chronic severe drooling}

Drooling, sometimes known as dribbling or poor saliva control, is a distressing problem. Drooling may be odorous; the secretions can cause chronic irritation of the facial skin; dehydration can occur if severe; and excessive drooling may damage clothing, books, and computer equipment. The care required for the individual increases the demands on family members. ${ }^{1}$ Poor saliva control may result in loss of self esteem. It is a major factor in impeding the successful integration of children and young adults into school, the community, and later the workplace. For adults with neurological conditions such as Parkinson Disease, the impact can be distressing, and individuals that drool have more difficulties with eating, speaking, and with social interactions than individuals with the same condition that do not drool. ${ }^{2}$

Many factors influence salivary flow including emotional state, environmental temperature, state of hydration, and the presence of food in the mouth. Quantification of salivary flow rate or drooling is challenging. Therefore, few studies documenting prevalence of the condition are available. Drooling has been reported as occurring in between $10 \%$ and $78 \%$ of children with cerebral palsy, and in $38 \%$ of a recent population-based cohort of 385 children from the Victorian Cerebral Palsy Register (manuscript in preparation). It also occurs in many individuals with intellectual disability and in other more unusual neurological and head and neck conditions. ${ }^{3}$ For those attending special education settings, the number may be higher and was reported to be present in $58 \%$ of children with cerebral palsy. ${ }^{4}$ Poor saliva control also occurs in acquired neurological conditions including Parkinson Disease, where it is estimated 
that it can be a problem in up to $70 \%-80 \%$ of individuals with this condition, ${ }^{5}$ following stroke and acquired brain injury, in motor neuron disease, ${ }^{6}$ and in those who have lost the structural integrity of their jaw, lips, or oral cavity due to tumors.

The etiology of drooling is multifactorial. Poor oromotor control, lack of lip closure, habitual open mouth posture, a head down posture, gingivitis, and dental caries may all contribute to the problem. Drooling is not generally caused by hypersalivation, but rather by oral motor dysfunction. An exception to this is in children with dyskinetic cerebral palsy, where increased flow may be a consequence of hyperkinetic oral movements. ${ }^{7}$ Drug-induced hypersalivation can also occur; for example, with clozapine and topiramate.

There are various treatment methods for drooling. Behavioral approaches include the use of verbal, auditory, or vibratory prompts to swallow or wipe, ${ }^{8}$ and prevention of mouthing of fingers or objects. ${ }^{9}$ Botulinum toxin injected into the salivary glands, usually under ultrasound guidance, is effective in the management of drooling, but the effects wear off after a period of time. ${ }^{10,11}$ Surgical procedures include tympanic neurectomy, submandibular gland excision, submandibular gland rerouting, sublingual gland excision, parotid duct rerouting, parotid duct ligation, and any combination of these procedures. ${ }^{12}$ However, medication remains one of the most common options.

\section{Review of pharmacology and pharmacokinetics}

The control of salivation is mainly under control of the parasympathetic nervous system. Acetylcholine is the active neurotransmitter, and hence anticholinergic drugs such as benztropine, glycopyrrolate (glycopyrronium), trihexyphenidyl hydrochloride (benzhexol hydrochloride), and scopolamine (hyoscine) patches (available in some parts of the world), are used for the treatment of drooling. These drugs reduce the production of saliva whilst they are being used and may improve drooling partially or completely. A recent systematic review of these drugs has provided some evidence for their efficacy, but no conclusion was reached as to which drug is preferable. ${ }^{13}$ The purpose of this review is to study one of the above drugs, glycopyrrolate.

Glycopyrrolate is a quaternary ammonium compound structurally related to atropine. It has been used extensively in anesthesia in premedication, during anesthesia and surgery, and with anticholinesterase drugs at the end of anesthesia for the antagonism of competitive neuromuscular block. Glycopyrrolate has been studied extensively in all these situations. ${ }^{14}$ However, more recently it has been used for saliva control. It is reported to be preferable to the other anticholinergic drugs because of its long duration of action and inability to cross the blood-brain barrier, ${ }^{15}$ thus minimizing central nervous system adverse effects such as sedation, dysphoria, and restlessness. ${ }^{16}$ It can be given orally (using tablet or liquid formulation) or via injection, but the latter is not indicated for a chronic problem such as drooling. Glycopyrrolate has poor oral availability at about $10 \%$, and absorption is inhibited by food, particularly high-fat meals. ${ }^{17}$ The solution for injection can be administered via enteral feeding tubes for those on nonoral feeding regimes if an oral liquid formulation is unable to be sourced. Glycopyrrolate has a rapid onset of effect: within 1-5 minutes when injected intravenously and within 15-30 minutes when given orally. ${ }^{18}$ Peak effect occurs within 1-4 hours with duration of action up to $8-12$ hours, depending on individual response. ${ }^{18,19} \mathrm{It}$ is reported to be particularly useful if a child is troubled by secretions at night time. ${ }^{9}$

\section{Efficacy studies, including comparative studies}

The literature describes the use of glycopyrrolate for drooling in two principal clinical situations: in children, mainly with cerebral palsy, who have poor saliva control, and in adults with neurological conditions such as Parkinson Disease. Additionally, there are reports of the use of glycopyrrolate in two further clinical situations. Firstly, there is a report of the use of nebulized glycopyrrolate for drooling in motor neurone disease. ${ }^{20}$ Secondly, it has been used in clozapineinduced sialorrhea. ${ }^{21,22}$ Clozapine is an atypical antipsychotic that is prescribed for relieving both the positive and negative symptoms of adolescents with treatment resistant schizophrenia. Sialorrhea is the second most common side effect of clozapine, and glycopyrrolate has been found to be useful in relieving this symptom.

\section{Studies in children with cerebral palsy and allied conditions}

Four studies are available.

1. In a study of 40 children and young adults with motor and/or cognitive disabilities, 36 of the cohort had reduced drooling in response to glycopyrrolate, two could not be assessed, and two received no benefit. Individual responses and side effects were monitored by telephone contact with parents or other caregivers. The most common side effect was behavioral change in the form of irritability, reported in five children, and others included 
skin flushing, epistaxis, headaches, urinary retention, and worsening constipation. Side effects resulted in discontinuation of treatment in 11 of the 40 participants, including two children with immediate allergic reactions. No further information was provided about the nature of their responses. This was an unblinded study, and response to therapy was based on subjective reports from parents or other caregivers. However, the broad final effective dose range of $0.01-0.82 \mathrm{mg} / \mathrm{kg}^{23}$ provides useful guidance for clinicians.

2. Stern conducted a study involving 24 children and young adults where parents/caregivers were asked to complete the Thomas Stonell and Greenberg scale ${ }^{24}$ on the effects of glycopyrrolate on severity and frequency of drooling. They were also asked to report any side effects. Twenty-two questionnaires were returned, and there was a highly statistically significant decrease in both severity and frequency of drooling with minimal side effects noted. ${ }^{25}$ The dose of glycopyrrolate was $0.04-0.1 \mathrm{mg} / \mathrm{kg}$ per day. This was also an unblinded study open to bias, given that parents completed the questionnaires retrospectively after the completion of the trial. However, the improvement in most of the children was also confirmed by their speech pathologists, adding some weight to the evidence.

3. In a survey of 54 parents/caregivers of children, most of whom had cerebral palsy, glycopyrrolate was used by 37 of 41 respondents, with significant improvement in drooling in the vast majority (95\%). Respondents described the amount of drooling using a five-point scale with 1 being no drooling and 5 being severe drooling. Side effects were reported in almost half (44\%) of the children, but discontinuation of the therapy was required in less than one-third. The mean dose was $0.051 \mathrm{mg} / \mathrm{kg} / \mathrm{dose}$ most commonly given three times daily, with a range of $0.01-0.14 \mathrm{mg} / \mathrm{kg} / \mathrm{dose}$. The mean doses did not differ significantly for those who experienced side effects than for those who did not. ${ }^{26}$ This study again had the same methodological limitations with parents responding to a postal questionnaire.

4. In a placebo-controlled, double-blind, crossover doseranging study, 39 children aged 4 years and older (mean age 10 years, 9 months) with developmental disabilities and drooling were studied. Most children (34) had cerebral palsy. After a 1-week observation period, each child was randomly assigned to either the drug or placebo treatment, each of which was 8 weeks long. At the end of the first arm, there was a 1 week washout period and a second week-long observation period, followed by the reciprocal arm, also 8 weeks in length. Drooling was scored on a scale ranging from 1 (never drools) to 9 (clothing, hands, and objects frequently become wet). Cartoon illustrations were used to instruct parents about the scale, and the drooling scores were obtained by a research assistant who made telephone calls at weekly intervals. Adverse effects were recorded on a scale from 1 (not at all) to 4 (very much). A total of 27 children completed the study. Of the 12 children who did not complete the study, eight dropped out because of adverse effects (one whilst receiving placebo), and four were excluded because of failure to comply with the protocol or because it was inconvenient for their families to continue. The dose of $0.10 \mathrm{mg} / \mathrm{kg}$ per dose, given three times daily, was effective in controlling drooling. All children completing the study demonstrated an improvement in drooling with glycopyrrolate. The mean drooling score in children randomized to the glycopyrrolate group improved from 7.52 at baseline to a best score of 1.85 while taking the drug. The mean best drooling score on glycopyrrolate (1.85) compared with placebo (6.33) was statistically different $(P<0.001)$. Approximately $20 \%$ of children experienced substantial side effects, enough to require discontinuation of treatment. ${ }^{27}$

There is thus only one randomized trial of glycopyrrolate, and in this study, there was a 30\% dropout rate. More studies are needed, particularly randomized controlled trials comparing glycopyrrolate with other medications and with other treatment modalities such as botulinum toxin. Moreover, research is needed to determine the most appropriate drug regimes to achieve effectiveness without side effects.

\section{Studies in adults with Parkinson Disease and other acquired neurological conditions}

1. A 4-week randomized, double-blind, placebo-controlled, crossover trial of glycopyrrolate taken as $1 \mathrm{mg}$ three times daily was conducted in 23 adults with Parkinson Disease. The severity of the saliva control problem was scored on a daily basis by the participants themselves or a caregiver using a sialorrhea scoring scale ranging from 1 (no sialorrhea) to 9 (profuse salivation). The sialorrhea score was significantly lower for the glycopyrrolate group (mean 3.8, standard deviation [SD] 1.6) compared with the placebo group (mean 4.6, SD 1.7, $P=0.011$ ). A clinically relevant improvement of at least $30 \%$ was seen in nine individuals taking glycoyrrolate versus one on placebo $(P=0.021)$. There were no significant differences in adverse events between glycopyrrolate 
and placebo treatment. Dry mouth was the most common adverse effect, followed by behavioral issues, described as "nervosity". This study provides Class 1 evidence that glycopyrrolate is more effective than placebo in reducing sialorrhea in individuals with Parkinson Disease. ${ }^{28}$

2. A randomized, double-blind, cross-over study was conducted to evaluate the efficacy and impact on cognition of glycopyrrolate and biperiden treatments for people with schizophrenia experiencing clozapine-induced sialorrhea. Sialorrhea and global cognitive function were assessed by using a drooling rating scale (DRS) and the Mini Mental State Examination (MMSE), respectively. Twelve individuals completed the study, and all participants treated with glycopyrrolate or biperiden had significantly reduced DRS scores. There was less impact on cognitive function with glycopyrrolate therapy. ${ }^{22}$ This was a small study, there was no control group and there were limitations in using the MMSE to evaluate global cognitive function.

Whilst both these studies undertaken in the adult population provide useful information, larger trials are required, involving larger numbers of individuals and more precise monitoring of side effects. As in the pediatric population, research is needed to determine the optimal drug regimes.

\section{Safety and tolerability}

Beneficial effects of glycopyrrolate can be seen in many individuals. Adverse effects are relatively common and include blurred vision, constipation, difficulty passing urine, flushed dry skin, and behavioral disturbance such as irritability or confusion. A reduction in salivary flow rates can result in thicker, more tenacious oral-pharyngeal secretions which may increase swallowing difficulties. Glycopyrrolate does not cross the blood-brain barrier, and it is reported that central nervous system side effects are greatly diminished. ${ }^{26}$ In the double-blind study described above, the most frequently noted adverse effects included behavioral changes, constipation, excessive dryness of the mouth, and urinary retention. ${ }^{27}$ As perspiration is reduced, some clinicians recommend temporary cessation of glycopyrrolate on days with extremely hot temperatures.

\section{Patient-focused perspectives such as quality of life, patient satisfaction/ acceptability, adherence, and uptake}

Limited information is available about patient satisfaction, adherence, and uptake. Control of drooling by whatever means has been shown to improve quality of life. In a study of 45 children with cerebral palsy, it was reported that control of drooling reduced care needs making daily care less demanding. ${ }^{1}$

In a study in which a seven-question survey on drooling was administered to 58 individuals with Parkinson Disease who were classified as either "droolers" or "non-droolers" and 51 age-matched controls, people with Parkinson Disease who had a drooling problem had worse quality of life and more difficulty speaking, eating, and socially interacting compared with individuals with Parkinson Disease who were non-droolers. ${ }^{2}$

For those that have a successful outcome following saliva control surgery, quality of life may be improved. ${ }^{29}$

\section{Conclusion, place in therapy}

Glycopyrrolate has been shown to have a place in therapy for the treatment of problematic sialorrhea in children and adults. However, monitoring for side effects is important, and care must be taken to provide appropriate advice to parents, caregivers, and the individuals themselves when prescribing this medication.

In children, both botulinum toxin and surgery are invasive. Glycopyrrolate can be particularly useful in four situations:

1. In younger children where maturation of oral function may still occur prior to embarking on more invasive treatments. Maturation of oral function can occur up to the age of approximately 6 years.

2. In older children with a relatively mild saliva control problem where medication such as glycopyrrolate can be used for social occasions.

3. As an alternative to surgery for those young people and their families who prefer a nonoperative approach.

4. In conjunction with a behavioral program as it will be easier for the latter to be successful when the volume of secretion is reduced.

It also has a place in adult neurological conditions where poor saliva control may be significantly interfering with quality of life.

More studies are needed to determine the effectiveness of glycopyrrolate at differing doses, to systematically identify side effects, both short and long term, and to compare glycopyrrolate both with other anticholinergic medication and with alternative forms of treatment. Measurement of drooling in itself poses a challenge, and studies need to carefully document methodology and treatment outcomes. The development of consensus guidelines has been suggested as a useful way forward and would provide assistance to clinicians and families to make evidence-based decisions. ${ }^{30}$ 


\section{Acknowledgments}

We acknowledge the support of State Trustees Australia Foundation (Eileen Lovegrove and Norman McKey subfunds), that provided funding to undertake studies to improve the management of children with saliva-control difficulties.

\section{Disclosure}

The authors report no conflicts of interest in this work.

\section{References}

1. Van der Burg JJ, Jongerius PH, Van Hulst K, et al. Drooling in children with cerebral palsy: effect of salivary flow reduction on daily life and care. Dev Med Child Neurol. 2006;48:103-107.

2. Leibner J, Ramjit A, Sedig L, et al. The impact of and the factors associated with drooling in Parkinson's disease. Parkinsonism Relat Disord. 2010;16:475-477.

3. Van De Heyning PH, Marquet JF, Creten WL. Drooling in children with cerebral palsy. Acta Otorhinolaryngol Belg. 1980;34:691-705.

4. Tahmassebi JF, Curzon ME, Curzon MEJ. Prevalence of drooling in children with cerebral palsy attending special schools. Dev Med Child Neurol. 2003;45:613-617.

5. Molloy L, Molloy L. Treatment of sialorrhoea in patients with Parkinson's disease: best current evidence. Curr Opin Neurol. 2007; 20:493-498.

6. Jackson CE, Gronseth G, Rosenfeld J, et al. Randomized double-blind study of botulinum toxin type B for sialorrhea in ALS patients. Muscle Nerve. 2009;39:137-143.

7. Erasmus CE, Van Hulst K, Rotteveel LJ, et al. Drooling in cerebral palsy: hypersalivation or dysfunctional oral motor control? Dev Med Child Neurol. 2009;51:454-459.

8. Van der Burg JJ, Didden R, Jongerius PH, et al. A descriptive analysis of studies on behavioural treatment of drooling (1970-2005). Dev Med Child Neurol. 2007;49:390-394.

9. Fairhurst CB, Cockerill H. Management of drooling in children. Arch Dis Child Educ Pract Ed. 2011;96(1):25-30.

10. Lim M, Mace A, Nouraei SA, Sandhu G, Nouraei SAR. Botulinum toxin in the management of sialorrhoea: a systematic review. Clin Otolaryngol. 2006;31:267-272.

11. Reid SM, Johnstone BR, Westbury C, Rawicki B, Reddihough DS. Randomized trial of botulinum toxin injections into the salivary glands to reduce drooling in children with neurological disorders. Dev Med Child Neurol. 2008;50:123-128.

12. Reed J, Mans CK, Brietzke SE, Reed J, Mans CK, Brietzke SE. Surgical management of drooling: a meta-analysis. Arch Otolaryngol Head Neck Surg. 2009;135:924-931.
13. Jongerius PH, van Tiel P, van Limbeek J, Gabreels FJ, Rotteveel JJ, Gabreels FJM. A systematic review for evidence of efficacy of anticholinergic drugs to treat drooling. Arch Dis Child. 2003;88:911-914.

14. Mirakhur RK, Dundee JW. Glycopyrrolate: pharmacology and clinical use. Anaesthesia. 1983;38:1195-1204.

15. Rautakorpi P, Ali-Melkkila T, Kaila T, et al. Pharmacokinetics of glycopyrrolate in children. J Clin Anesth. 1994;6:217-220.

16. Tscheng DZ. Sialorrhea - therapeutic drug options. Ann Pharmacother. 2002;36:1785-1790.

17. Rautakorpi P, Manner T, Ali-Melkkila T, Kaila T, Olkkola K, Kanto J. Pharmacokinetics and oral bioavailability of glycopyrrolate in children. Pharmacol Toxicol. 1998;83:132-134.

18. Hodding JH, Kraus DM, Taketomo CK, editors. Pediatric Dosage Handbook. Hudson: Lexi-Comp; 2009.

19. Cada D, Levien T, Baker D. Formulary drug reviews-glycopyrrolate oral solution. Hosp Pharm. 2010;45:939-943.

20. Strutt R, Fardell B, Chye R. Nebulized glycopyrrolate for drooling in a motor neuron patient. J Pain Symptom Manage. 2002;23:2-3.

21. Robb AS, Lee RH, Cooper EB, et al. Glycopyrrolate for treatment of clozapine-induced sialorrhea in three adolescents. $J$ Child Adolesc Psychopharmacol. 2008;18:99-107.

22. Liang CS, Ho PS, Shen LJ, et al. Comparison of the efficacy and impact on cognition of glycopyrrolate and biperiden for clozapine-induced sialorrhea in schizophrenic patients: a randomized, double-blind, crossover study. Schizophr Res. 2010;119:138-144.

23. Blasco PA, Stansbury JC. Glycopyrrolate treatment of chronic drooling. Arch Pediatr Adolesc Med. 1996;150:932-935.

24. Thomas-Stonell N, Greenberg J. Three treatment approaches and clinical factors in the reduction of drooling. Dysphagia. 1988;3:73-78.

25. Stern LM. Preliminary study of glycopyrrolate in the management of drooling. J Paediatr Child Health. 1997;33:52-54.

26. Bachrach SJ, Walter RS, Trzcinski K. Use of glycopyrrolate and other anticholinergic medications for sialorrhea in children with cerebral palsy. Clin Pediatr. 1998;37:485-490.

27. Mier RJ, Bachrach SJ, Lakin RC, Barker T, Childs J, Moran M. Treatment of sialorrhea with glycopyrrolate: a double-blind, doseranging study. Arch Pediatr Adolesc Med. 2000;154:1214-1218.

28. Arbouw ME, Movig KL, Koopmann M, et al. Glycopyrrolate for sialorrhea in Parkinson disease: a randomized, double-blind, crossover trial. Neurology. 2010;74:1203-1207.

29. Syeda F, Ahsan F, Nunez DA. Quality of life outcome analysis in patients undergoing submandibular duct repositioning surgery for sialorrhoea. J Laryngol Otol. 2007;121:555-558.

30. Parr JR, Buswell CA, Banerjee K, et al. Management of drooling in children: a survey of UK paediatricians' clinical practice. Child Care Health Dev. Epub 2011 Mar 11.
Degenerative Neurological and Neuromuscular Disease

\section{Publish your work in this journal}

Degenerative Neurological and Neuromuscular Disease is an international, peer-reviewed, open access journal focusing on research into degenerative neurological and neuromuscular disease, identification of therapeutic targets and the optimal use of preventative and integrated treatment interventions to achieve improved outcomes, enhanced

\section{Dovepress}

survival and quality of life for the patient. The manuscript management system is completely online and includes a very quick and fair peer-review system. Visit http://www.dovepress.com/testimonials.php to read real quotes from published authors. 